\title{
Hermeneutika Al-Our'an Kontekstual: Metode Menafsirkan Al-Qur'an Abdullah Saeed
}

\author{
Hatib Rachmawan \\ Universitas Ahmad Dahlan, Yogyakarta. \\ Email:khatib_rachmawan@yahoo.com
}

\begin{abstract}
Quranic exegesis has a special place in the development of Islamic intellectual tradition and civilization at large. As the main source of Islamic teaching, for centuries Muslims have attempted to understand the various meanings of the Qur'an in order to be in line with the current needs of the society through the process of contextualization. In this article, the author presents and explains the way in which Abdullah Saeed, a professor in Islamic studies from the the University of Melbourne, Australia, contextualize the meaning of the Quran. In particular, this article analyzes some methodological aspects proposed by Saeed in the qontextualization of the Qur'an: 1) identifying the world of the text; 2) analyzing text critically; 3) connecting the text to the early Islamic community as the first receivers; and 4) relating the text to the current needs of society.

Keywords: Quranic exegesis, Abdullah Saeed, tafsir methodology, contextualization.
\end{abstract}

\section{ABSTRAK}

Tafsir al-Quran memiliki tempat yang penting dalam perkembangan tradisi intelektual Muslim dan peradaban Islam secara umum. Sebagai sebuah sumber utama ajaran Islam, kaum Muslim selama berabab-abad mencoba memahami makna al-Quran agar sesuai dengan kebutuhan zaman, salah satunya dengan cara kontekstualisasi. Dalam tulisan ini, penulis membahas gagasan kontekstualisasi penafsiran al-Qur'an yang dilakukan Abdullah Saeed seorang guru besar bidang studi Islam di Australia. Secara khusus penulis menganalisis aspek-aspek metodologis dari pandangan Abdullah Saeed dalam melakukan kontekstualisasi tafsir al-Qur'an. Penulis berkesimpulan bahwa Abdullah Saeed menawarkan empat langkah operasional penafsiran kontekstual yaitu, 1) mengidentifikasi dunia teks; 2) menganalisis teks secara kritis; 3) menganalisis teks dikaitkan dengan komunitas awal penerima wahyu dan 4) menganalisis teks dengan kondisi saat ini. Kata Kunci: tafsir al-Quran, Abdullah Saeed, metodologi tafsir, kontekstualisasi

\section{PENDAHULUAN}

Al-Qur'an adalah petunjuk untuk semua manusia (hudan linnas). Al-Qur'an adalah rahmat bagi alam semesta. Dua kalimat tersebut menunjukan bukti bahwa al-Qur'an yang turun 15 abad yang lalu di Hijaz bukan untuk bangsa Arab saja, melainkan untuk seluruh umat manusia di seluruh belahan dunia. Semua intelektual muslim sangat sepakat dengan pernyataan tersebut. AlQur'an diwahyukan dengan bahasa Arab oleh Allah agar mudah dipahami. ${ }^{1}$ Sehingga tidak ada alasan bagi orang- 
orang Arab pada waktu itu untuk membantahnya. Al-Qur'an diturunkan secara berangsur-angsur untuk merespon kondisi sosial dan masalah yang dihadapi Rasulullah di Mekah, Madinah dan beberapa tempat yang disinggahinya. Dari fakta-fakta tersebut menunjukkan bahwa al-Qur'an benar-benar hadir untuk merespon kondisi Arab. Maka, jika seseorang hendak memahami al-Qur'an, ia harus paham bahasa Arab, ${ }^{2}$ dan paham kondisi sosio kultur masyarakat Arab.

Pertanyaannya adalah bagaimana membawa makna lokal al-Qur'an yang memiliki setting historis Arab ke dunia luar yang memiliki kondisi sangat berbeda? Pertanyaan inilah di era sekarang menjadi masalah. Setidaknya ada dua karakter umat Islam dalam merespon pertanyaan tersebut. Pertama, yang berpandangan bahwa makna alQur'an dan budaya Arab tidak dapat dipisahkan, sehingga dalam penyebarannya kedua hal tersebut harus dibawa beriringan. Kedua, yang berpandangan bahwa nilai-nilai al-Qur'an saja yang dibawa, sementara budaya Arabnya ditinggalkan, mengikuti budaya setempat atau lokal baru yang disinggahinya. Pendapat pertama akan menghasilkan Islamisasi dan Arabisasi, sementara yang kedua akan menghasilkan Islamisasi dan kontekstualisasi. Pertanyaannya kemudian, bagaimanakah melakukan proses kontekstualisasi tersebut? Bagaimana agar nilai-nilai al-Qur'an dapat hidup di daerah baru di zaman yang baru seperti sekarang? Tulisan ini berupaya menjawab pertanyaan tersebut.

Sesungguhnya konsep kontekstualisasi alQur'an di awal abad 19 sudah bermunculan, seiring kuatnya dorongan untuk membuka pintu ijtihad yang selama beberapa abad sempat tertutup. Gagasan kontekstulisasi ini baru benar-benar nampak dan dikukuhkan oleh Fazlur Rahman dengan metode hermeneutik gerak ganda (double movement). Pemikiran Rahman ini kemudian menyebar ke berbagai belahan dunia bersama para pemikir Islam progresif lainnya.

Abdullah Saeed adalah salah seorang intelektual kebangsaan Oman yang tertarik mensistematisasikan pemikiran Rahman. Konsep kontekstualisasi Rahman dengan double movement-nya masih menyisakan kekurangan, meskipun sukses menanamkan dasar dan pondasi dalam hal pembaharuan model penafsiran, khususnya gagasan kontekstualisasi. Rahman tidak begitu menjelaskan mengenai langkah-langkah kontekstualisasi secara terperinci. Rahman juga tidak mengaitkan masalah kontekstualisasi dengan perkembangan ilmu pengetahuan. Kekurangan tersebut kemudian disikapi secara cerdas oleh Saeed. Sehingga nampaklah sebuah metode kontekstualisasi al-Qur'an yang utuh. Tulisan ini akan membahas bagaimana gagasan kontekstualisasi penafsiran al-Qur'an Saeed yang secara implisit terpengaruh hermeneutika Gadamer. Kemudian juga akan dibahas bagaimana langkah-langkah Saeed dalam melakukan kontekstualisasi? Dua masalah inilah yang akan dipaparkan panjang lebar berikut ini.

\section{BIOGRAFI ABDULLAH SAEED}

Abdullah Saeed adalah intelektual muslim progresif ternama berkebangsaan Oman, yang terbilang relatif muda. Ia lahir di kota Maldives, dan menjadi imigran di Australia. Sebagai pendatang ia tidak berkecil hati, justru sebaliknya hal tersebut malah memberikan dorongan kuat untuk terus belajar. Ia akhirnya menggapai puncak 
karirnya di Australia, sebuah daerah multi etnis sekuler, sebagai Profesor di Bidang Islamic Studies di University of Melbourne. ${ }^{3}$

Karir pendidikannya diawali ketika Saeed mengambil jurusan Bahasa Arab pada Institute of Arabic Language di Saudi Arabia, dan pada tahun 1977 ia mendapatkan gelar BA. Kemudian melanjutkan program magister (MA) dalam bidang Applied Linguistic (Linguistik Terapan) dan doktoral (Ph.D) dalam bidang Islamic Studies di University of Melbourne. Tahun 1993, ia bergabung di Department of Asian Languages and Anthropology pada University of Melbourne sebagai dosen, kemudian meningkat menjadi dosen senior tahun 1996, serta menjadi anggota asosiasi Professor pada tahun 2000. Saat ini ia menjadi direktur National Center of Excelence for Islamic Studies dari University of Melbourne. Ia juga pernah mendapatkan penghargaan dari Sultan Oman sebagai Professor Bidang Bahasa Arab dan Islamic Studies tahun 2003. ${ }^{4}$

Saeed mengajarkan bahasa Arab dan Islamic Studies untuk mahasiswa S1, S2, dan S3. Materi-materi yang diajarkannya antara lain: Great Texts of Islam: Qur'an (Al-Qur'an: Kitab Suci Umat Islam); Muslim Intellectuals and Modernity (Intelektual Muslim dan Modernitas); Great Empires of Islamic Civilization (Sejarah Kerajaan Besar Islam); Islamic Banking and Finance (Perbankan Syari'ah); Qur'anic Hermeneutics (Hermeneutika AlQur'an); Methodologies of Hadith (Metodologi Hadis); Methods of Islamic Law (MetodeMetode Hukum Islam); Religious Freedom in Asia (Kebebasan Beragama di Asia); Islam and Human Rights (Islam dan Hak Asasi Manusia); dan Islam and Muslims in Australia (Islam dan Muslim di Australia). Saeed juga terlibat dalam dialog antar iman, antara umat
Kristiani dan Muslim, antara umat Yahudi dan Muslims. Ia juga sering melakukan lawatan dan kunjungan ke berbagai daerah, misal ke Amerika Utara, Eropa, Timur Tengah, Asia Selatan dan Asia tenggara. Ia memiliki radius pergaulan yang luas di kalangan profesional dan hubungan research di berbagai belahan dunia.

$$
\text { Karya-karya Saeed cukup beragam. }
$$

Diantara yang dipublikasikan antara lain: Islamic Banking and Interest: A Study of the Prohibition of Riba and Its Contemporary Interpretation (1997), yang merupakan disertasi Abdullah Saeed. Essential Dictionary of Islamic Thought (2001), Muslim Communities in Australia (2002), Freedom of Religion, Apostasy and Islam (2003), Islam in Australia (2003), Islam and Political Legitimacy (2003), Interpreting the Quran: Towards a Contemporary Approach (2006), 'Contextualizing' sebuah artikel yang ditulis dalam The Blackwell Companion to the Qu'ran (2006) yang dieditori oleh Andrew. Rippin, 'Muslims in Australia' in Australia and the Middle East: a front line relationship (2006), Islamic Thought: An Introduction (2006). Muslims in the West Choose between Isolationism and Participation (2006), Creating a Culture of Human Rights from a Muslim Perspective (tulisan yang dipublikasikan pada jurnal Cultivating Wisdom, Harvesting Peace, edisi 10. Aug-2006 sampe 13-Aug-2006), Approaches to the Qur'an in Contemporary Indonesia (2006) Abdullah Saeed sebagai editor, The Qur'an: An Introduction (2008), Islamic Political Thought and Governance: Critical Concepts in Political Science (2010), Reading the Qur'an in the Twenty-first Century (2012) yang tahun depan akan diterbitkan. ${ }^{5}$

\section{PETA HERMENUTIKA AL-OUR'AN}

Jika sejarah hermeneutika dipotret maka 
dapat dibagi menjadi tiga bentuk, pertama, hermeneutika sebagai alat untuk menafsirkan teks mitos sebagaimana yang berkembangan di zaman Yunani Kuno. Kedua, hermeneutika sebagai alat untuk menafsirkan teks kitab suci (khususnya Bible). ${ }^{6}$ Dan ketiga, adalah hermeneutika umum, yang berkembang dan banyak digunakan untuk mencari objektifitas makna (otentisitas makna). ${ }^{7}$ Jika melihat perkembangan sekarang, umat Islam banyak mengambil model yang terakhir. Misal pemikiran Gadamer dan Paul Ricoeur. Jadi sangat tidak tepat jika umat Islam anti pati terhadap hermeneutik, dan terburu-buru menyimpulkan bahwa hermeneutik sangat cocok untuk Bible namun tidak cocok untuk al-Qur'an.

Alasan yang sering digunakan adalah karena Bible bermasalah dalam kodifikasinya (sejarah pembukuannya) maka untuk mendapatkan makna yang objektif dari teks aslinya dibutuhkan hermeneutik. Sementara al-Qur'an secara historis tidak bermasalah, maka untuk apa hermeneutik? Ketika hermeneutik digunakan, seolah-olah pengguna dituduh sebagai orang yang mencurigai al-Qur'an tidak otentik lagi. Argumen tersebut terlalu menyederhanakan persoalan. Padahal al-Qur'an telah memancing para ulama untuk berkarya. Ratusan tafsir telah dihasilkan dari zaman ke zaman. Pertanyaannya adalah manakah dari sekian tafsir tersebut yang paling benar? Manakah dari sekian tafsir tersebut yang paling sesusai dengan zaman sekarang? Manakah dari sekian tafsir yang paling sesuai dengan ilmu pengetahuan? Mulai dari Rahman hingga Saeed sesungguhnya fokus pada wilayah ini. Mereka fokus pada upaya pencarian makna yang relevan terhadap zamannya. Bukanya mempertanyakan keotentikan al-Qur'an.

Hermeneutik berasal dari bahasa Yunani 'hermeneuin', yang artinya menafsirkan (to interpret). Hermeneutik dapat didefinisikan sebagai disiplin ilmu yang concern terhadap sifat dan karakteristik penafsiran. Objek dari proses ini adalah teks. Maka hermeneutik dapat juga disebut sebagai langkah-langkah operasional memahami hal-hal yang berhubungan dengan teks. ${ }^{8}$ Dari definisi tersebut maka hermeneutika al-Qur'an dapat disebut dengan langkah-langkah operasional dalam memahami teks al-Qur'an dan hal-hal yang terkait.

Sebagaimana layaknya sebuah teks, alQur'an lahir tidak dengan sendirinya. Ada faktor-faktor yang melatarbelakangi kemunculannya. Dalam ulumul Qur'an hal ini disebut dengan asbab an-nuzul. ${ }^{9}$ Dalam mengoperasikan hermeneutik, asbab an-nuzul hanya menjadi salah satu sumber informasi. Maksudnya hermeneutik masih membutuhkan banyak sumber informasi lainnya. Maka dari itu Esack menjelaskan bahwa hermeneutik merupakan cara menafsirkan teks yang melibatkan berbagai keterangan-dapat berupa: bahasa (language), budaya (culture), sejarah (histories), dan sebagainya-yang terkait dengan teks tersebut. ${ }^{10}$

Selaras dengan hal di atas, berarti alQur'an yang diwahyukan 15 abad yang lalu dalam bahasa Arab di daerah Hijaz, secara otomatis menjadi objek kajian hermeneutik. Sehingga jika ada seseorang yang ingin memahami al-Qur'an, maka ia semestinya juga memahami setting historis Hijaz, ${ }^{11}$ selain sudah tentu memahami bahasa Arab. ${ }^{12}$

Dengan meniru hermeneutika Gadamer, Essack menyimpulkan ruang lingkup 
pembahasan hermeneutik al-Qur'an dalam tiga bentuk, yakni; 1) pada ranah sifat dan karakteristik teks (nature of text); 2) pada ranah proses memahami teks (understanding text); 3) pada ranah metode memahami dan menafsirkan teks yang mana antara penafsir (interpreter) dan pendengar (audience) memiliki asumsi dan horizon sendiri-sendiri (fusion of horizon). Isu yang terakhir ini menuntut sebuah metodologi yang dapat menggabungkan horizon penafsir dan pendengar. ${ }^{13}$ Ranah tersebut kalau disederhanakan urutannya berikut: ontologis, historis, dan metodologis. Jika ranah ini diterapkan pada wilayah al-Qur'an maka pada wilayah ontologis yang menjadi titik sentral pembahasannya adalah bahasa. Pada ranah historis pembahasannya sangat luas. Masuk di dalamnya sosial, ekonomi, politik, dan sebagainya. Pada wilayah metodologi masuk di dalamnya berbagai ilmu pengetahuan, termasuk di dalamnya social sciences, nature sciences, dan humanities contemporer, yang mana ketiga ilmu tersebut berperan sebagai pendekatan untuk menjawab permasalahanpermasalahan yang ada. Jika digambarkan dalam tabel sebagai berikut:

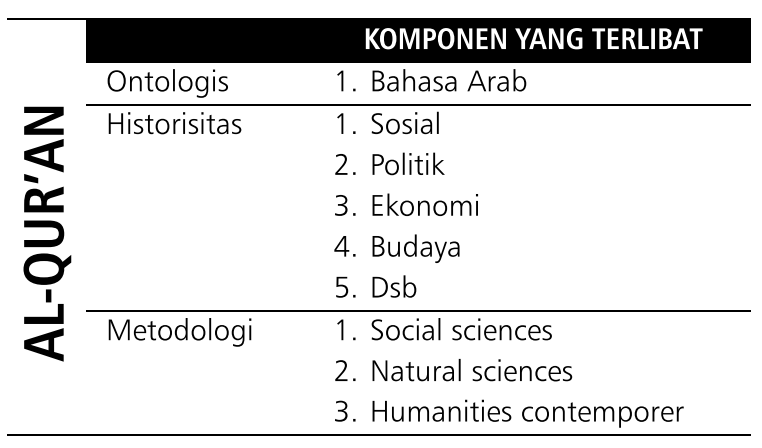

Pertanyaannya kemudian, mengapa hermeneutik begitu dianggap perlu dalam penafsiran al-Qur'an? Esack meyakini bahwa hermeneutik dapat digunakan untuk memberikan makna yang objektif terhadap al-Qur'an. Selama ini metode penafsiran alQur'an terjebak pada kepentingankepentingan ideologis, Sunni-Syiah, Mu'tazilah-Asy'ari, dan sebagainya. ${ }^{14}$ Menjawab pertanyaan tersebut Saeed memandang agak berbeda. Penggunaan hermeneutik menurutnya memberikan celah bagi hadirnya makna baru yang tidak tunggal. Sehingga audiens dihadapkan pada variasi penafsiran dan penafsiran tidak terjebak otoritarianisme, sebab yang layak otoriter hanyalah al-Qur'an. Hermeneutik mencoba memberikan makna baru yang relevan dengan zamannya. Sebab selama ini penafsiran klasik menuju pada makna tunggal yang otoritatif. ${ }^{15}$ Akibatnya karya tafsir mengalami kesenjangan dengan kondisi sekarang. Sub bab berikutnya akan membahas pemikiran hermeneutik al-Qur'an menurut Saeed.

\section{HERMENEUTIKA KONTEKSTUAL ABDULLAH SAEED}

Gagasan Saeed dalam studi al-Qur'an yang paling populer adalah metode penafsiran kontekstual, penulis menyebutnya hermeneutika al-Qur'an kontekstual. Kata context (konteks) dalam kamus digital Encarta berarti surrounding condition (lingkungan sekitar). Sementara itu contextualize (konteksualisasi) bermakna to place a word, phrase, or idea within a suitable context (menempatkan kata, frase atau ide dalam konteks yang sesuai). Jadi kontekstualiasi alQur'an adalah menempatkan makna alQur'an sesuai dengan kondisinya atau dalam bahasa lainnya menafsirkan al-Qur'an sesuai dengan kondisi zamannya.

Saeed menyebut dirinya sebagai seorang 'contextualist'. Ia memaknai kontekstualisasi 
sebagai proses menjadikan wahyu yang diturunkan 15 abad yang lalu dapat menghasilkan makna yang dibutuhkan umat Islam saat ini. Pernyataan lengkapnya sebagai berikut:

I will refer to this approach as 'Contextualist.

The thrust of my argument, therefore, is towards a more flexible approach to interpretation of these texts by taking into consideration both the socio-historical context of the Qur'an at the time of revelation in the first/seventh century and the contemporary concerns and needs of Muslims today. ${ }^{16}$

Memang tepat ketika Saeed mengaku sebagai kontekstulis. Sebab metode tersebut digunakan secara konsisten di beberapa karyanya, antara lain Islamic Banking and Interest: A Study of the Prohibition of Riba and Its Contemporary Interpretation (1997). Dalam buku tersebut, ketika menjelaskan riba, ia selalu mengaitkan kondisi sosial ekonomi Hijaz. Hal ini nampak dalam penafsirannya terhadap surah Ali Imran ayat 130:

Ayat ini berada dalam konteks sebagai pengingat kepada orang-orang Muslim mengenai apa yang salah di Perang Uhud, saat sebuah kemenangan yang potensial berubah menjadi kekalahan mematikan, berakibat gugurnya tujuh puluh pria muslim...Situasi semacam ini mempersyaratkan agar bantuan yang diberikan kepada orang-orang yang memerlukan itu berdasarkan derma, bukan berdasarkan riba. Jadi, segera setelah menyatakan bahwa umat Islam tidak boleh terlibat dalam transaksi riba, al-Qur'an memerintahkan mereka untuk segera bertaqwa kepada Allah, takut terhdap neraka, mematuhi Allah dan Rasulullah, dan bersegera kepada ampunan dari Tuhan, dengan menggambarkan orang yang bertaqwa sebagai "orang-orang yang menafkahkan (hartanya) di saat kelapangan dan kesempitan" demi menghilangkan penderitaan orang-orang yang memerlukan. ${ }^{17}$

Contoh lainnya nampak dalam karyanya Muslim Communities in Australia (2002). Dalam bukunya tersebut, ia mengharapkan bahwa seorang muslim Australia harus dapat menyesuaikan diri dengan kondisi di Australia-proses penyesuaian diri butuh proses kontekstualisasi. Ia juga ingin menegaskan bahwa muslim Australia berbeda dengan muslim di tempat lainnya. Hal ini nampak dalam kutipan berikut:

Muslim had to explain what Islam meant to them, particularly in the context of Australian life. They had to demystify concept like jihad and hijab and to convince an increasingly skeptical audience that Islam itself is not to blame for the atrocities committed by extremists and radicals among them. ${ }^{18}$

Gagasan kontekstualisasi penafsiran tersebut lebih disistematisasikan oleh Saeed dalam bukunya Interpreting the Qur'an: Towards a Contemporary Approach (2006).

Menurutnya kontekstualisasi adalah kebutuhan zaman. Sebab, selama 150 tahun, dunia sudah mengalami kejadian-kejadian luar biasa, yang mana hal tersebut membawa perubahan cara pandang (world view) dan cara beragama penduduk dunia, muslim atau non muslim. Kejadian-kejadian tersebut antara lain: globalisasi, migrasi, revolusi teknologi dan ilmu pengetahuan, penjelajahan luar angkasa, penemuan-penemuan arkeologi, evolusi dan genetik, pendidikan dan tulisan, dan lain sebagainya. ${ }^{19}$ Jadi konteksualiasi secara tidak langsung ingin mengatakan 
bahwa agama harus mengikuti perubahan zaman, bukan zaman yang harus mengikuti al-Qur'an.

Gagasan kontekstualisasi al-Qur'an sebenarnya sudah lama dicetuskan oleh Fazlur Rahman, intelektual Pakistan, dengan teorinya double movement (gerak ganda). Fazlur Rahman berpandangan bahwa dalam membaca al-Qur'an seseorang harus kembali ke masa lalu, memahami konteks dimana alQur'an diturunkan, kemudian membawa nilai-nilai masa lalu tersebut pada saat ini. Hal ini berbeda dengan Qiyas, yang hanya melihat kesamaan peristiwa, namun bukan konteks. ${ }^{20}$ Saeed sangat terinspirasi dengan gagasan tersebut. Keunggulan dari pemikiran Saeed, adalah ia mampu memberi sistematika dan langkah-langkah operasional dalam melakukan kontekstualisasi al-Qur'an. Hal ini akan dibahas dalam sub bab tersendiri.

\section{PRINSIP-PRINSIP HERMENEUTIKA KONTEISSTUAL ABDULLAH SAEED}

Setidaknya ada beberapa prinsip hermeneutika kontekstual Abdullah Saeed yang harus dipahami. Prinsip-prinsip ini penulis simpulkan untuk memudahkan pembaca memahami Saeed lebih dalam, bukan untuk mensimplifikasi pemikirannya. Beberapa prinsip tersebut antara lain; 1) AlQur'an lahir dalam setting socio-historical context tertentu; 2) Kontekstualisasi merupakan berakar dari tradisi Islam; 3) Kontekstualisasi muncul dari penafsiran bil arra'yi; dan 4) Karakteristik teks al-Qur'an berimplikasi pada makna.

\section{Al-Qur'an Terikat Socio-Historical Con-} text

What is the Qur'an? Where did it come from?

How have Muslims interacted with the Quran in the past, and how do they view it today? How does the Qur'an interact with the scriptures of the other major Abrahamic religions Judaism and Christianity? ${ }^{21}$

Pertanyaan-pertanyaan Saeed di atas menghantarkan pembaca pada sebuah kesadaran sejarah. Bahwa al-Qur'an tidak lahir dengan sendirinya, meskipun hanya Allah yang paling tahu motif-motif mengapa harus menurunkan al-Qur'an. Sebagai seorang ilmuan mempertanyakan konteks (history) al-Qur'an sangatlah penting. Karena dengan mengetahui konteks dimana alQur'an lahir akan memudahkan seorang muslim berinteraksi dengan masa lalu, dan dengan agama-agama lainnya, khususnya Abrahamic religion, Yahudi dan Kristen. Dengan mengetahui konteks seorang muslim juga dapat mengetahui alasan-alasan apa yang menyebabkan sebuah hukum-etis (syari'ah) diputuskan dan diproduksi. ${ }^{22}$ Jadi memahami konsteks sosial-historis al-Qur'an menjadi semacam syarat penafsiran. Tanpa pemahaman ini sebuah penafsiran akan terlihat sangat janggal, bahkan cenderung tidak berguna apa-apa, ibarat seseorang berbicara di ruang hampa.

Saeed membagi konteks al-Qur'an menjadi dua bentuk, yakni konteks yang luas (broad context) dan konteks yang sempit (narrow context). Konteks yang luas adalah the overall content of the Qur'an, as well as the broader framework of the prophet's life and the first Muslim community. It includes worldview presented by the Qur'an, the values it emphasizes and the overall guidance (which by definition varies depending on how one approaches the Qur'an) it provides. ${ }^{23}$ Jadi jelas yang dimaksud konteks luas adalah asbabun nuzul makro. Ia juga memperinci konteks-konteks yang 
dimaksud apa saja, sebagai berikut;

1. Konteks sosial, lingkungan dan politik yang mempengaruhi bangsa Arab.

2. Pesan-pesan yang diterima dan yang direfleksikan al-Qur'an terhadap konteks pada waktu itu.

3. Praktek-praktek budaya dan nilai-nilai yang berhubungan dengan al-Qur'an pada waktu itu.

4. Bahasa-bahasa yang digunakan al-Qur'an untuk mengekspresikan pesan-pesan moral dan cara menafsirkan setiap pesan yang dipengaruhi oleh budaya pada waktu itu. ${ }^{24}$

Adapun konteks sempit (narrow context) yang dimaksud Saeed adalah a sentence and word that signal an idea in a given part of the Qur'an. ${ }^{25}$ Pendapat Saeed mengenai hal ini sama dengan konsep asbabun nuzul ulama klasik, atau dalam bahasa lainnya disebut dengan asbabun nuzul mikro. Dari sini dapat disimpulkan kontekstualisasi yang diinginkan Saeed adalah meramu kondisi mikro dan kondisi makro dimana sebuah teks lahir, dan yang terpenting adalah sejauh mana kedua hal tersebut mempengaruhi pembentukan sebuah hukum.

\section{KONTEKSTUALISASI MERUPAKAN TRADISI ISLAM}

Munculnya wacana kontekstualisasi sering dianggap hal baru yang merupakan dampak dari infiltrasi pemikiran barat. Padahal kontekstualisasi sesungguhnya sama sekali bukan hal baru, melainkan tradisi yang sudah berkembang sejak zaman para sahabat (companion). Beberapa sahabat, ada yang nampak sangat tekstual, terpaku pada teksteks dan pesan yang ditinggalkan Nabi, sementara ada yang progresif, mecoba melakukan pemaknaan ulang terhadap pesan yang ditinggalkan Nabi.

Salah satu contoh sahabat yang sangat tekstual adalah Abu Bakar. Kelembutan hati Abu Bakar, membuatnya tidak berani jika harus bertentangan dengan pendapat Rasulullah. Pada waktu itu Abu Bakar diminta oleh Umar untuk mengeluarkan kebijakan mengenai qodifikasi al-Qur'an. Namun Abu Bakar menolaknya dengan alasan Rasulullah pernah melarang pencatatan al-Qur'an. Meskipun, setelah didesak, akhirnya Abu Bakar mau menerima usulan tersebut. Cara berpikir Abu Bakar ini mencerminkan ketaatan seorang tekstualis, dan hal ini bukanlah hal negatif.

Adapun contoh sahabat yang kontekstual adalah Umar bin Khattab. Tokoh ini banyak memutuskan perkara yang dianggap kontroversial. Karena keputusan-keputusannya tidak merujuk pada pendapat Rasulullah, bahkan dalam beberapa hal sangat bertentangan. Sebagai contoh ketika Umar dan pasukannya berhasil menaklukan Iraq, ia tidak membagibagikan tanah kepada para pasukannya, melainkan tetap milik penduduk setempat. ${ }^{26}$ Kebijakannya itu memunculkan banyak kecaman di internal sahabat. Namun Umar, bukan tanpa alasan, dia khawatir dengan dibagi-bagikannya tanah kepada para sahabat justru akan menimbulkan masalah baru, yakni kemiskinan dan kelaparan di daerah yang baru saja ditaklukkan. Karena alasan itulah Umar, tidak menggunakan apa yang sudah dijalani umat Islam bersama Rasulullah. Gambaran bahwa kontekstualisasi merupakan tradisi yang sudah berkembang sejak masa lalu digambarkan Saeed sebagai berikut:

Many Textualists argue that Muslims of the twenty-first century have no authority to change anything in the shari'ah or even to reinterpret 
it. This argument appears unsustainable on several fronts. First, reinterpretation and change are not new in Islam. It occurred in the Qur'an and sunnah during the formative period and at the time of the Companions. It was practiced by many leading jurists and theologians. For example, Umar b. al-Khattab changed a number of rulings clearly stated in the Qur'an and sunnah. An example is Umar's refusal to distribute the land of Iraq as booty to the Muslim army after its conquest, even though there is an instruction in the Qur'an that appears to command Muslims to distribute such booty. But when circumstances changed and the 'public interest' demanded it, Umar believed he could choose a different way. In other words, if a practice or ruling fulfilled a specific social function, reinterpretation was possible if the context of the ruling changed. ${ }^{27}$

\section{KONTEISSTUALISASI MEMBUTUHIKAN PENAFSIRAN BI AR-RA'YI}

Kuntowijoyo membagi sejarah umat Islam Indonesia dalam beberapa fase, yakni mitos, ideologi dan ilmu. ${ }^{28}$ Kategorisasi ini jika diangkat dan pada wilayah global sangat cocok. Sebab perkembangan sejarah bangsa hampir memiliki kesamaan. Kondisi umat Islam saat ini masuk fase ilmu. Dimana industrialisasi sangat mempengaruhi cara berpikir. Rasionalisme mewarnai semua sendi kehidupan. Trend pemikiran yang dominan adalah yang ilmiah (rasional).

Gagasan Kuntowijoyo di atas meninggalkan sebuah pertanyaan. Bagaimana tipikal masyarakat Islam yang berkembang dalam fase ilmu? Dalam menjawab pertanyaan tersebut Saeed memberikan gambaran continuity and changes pada fase tersbeut. Masyarakat Islam pada fase ini diawali dari modernis, kemudian berkembang menjadi neo-modernis, saat ini yang paling mutakhir menjadi progresif (muslim progressive). Salah satu ciri dari pemikiran muslim progresif adalah digunakannya metodologi ijithad baru, ${ }^{29}$ yakni kontekstualisasi sebagaimana yang topik pembahasan.

Dengan narasi di atas, maka sesungguhnya tafsir bil ra'yi (based-reason exegesis) merupakan metode penafsiran yang sangat sesuai dengan kondisi zaman umat Islam saat ini, selain sebagai misi dari muslim progresif. Dimana kemajuan ilmu pengetahuan sudah merubah banyak cara beragama umat Islam. Selain itu, metode kontekstualisasi banyak dipengaruhi oleh hermeneutik modern, ${ }^{30}$ yang mana salah satu cirinya adalah menggunakan social sciences dan natural sciences dalam analisis. Jadi tafsir bil ra'yi merupakan kebutuhan metodis dari kontekstualisasi.

Tafsir bil ra'yi (based-reason exegesis) merupakan kelanjutan dari tafsir ilmi. Para ulama klasik sudah mengindikasikan hal ini. Saeed dengan mengutip pendapat Qurtubi menyatakan bahwa ijtihad (independent reason) merupakan hal penting untuk mengembangkan sebuah penafsiran alQur'an yang sangat memadai. Qurtubi, juga menyatakan bahwa ijtihad harus bersandar kepada tradisi (riwayat). ${ }^{31}$ Dari pendapat tersebut dapat ditarik sebuah kesimpulan bahwa penggunaan reason dalam penafsiran sangatlah penting. Maka tidak salah jika Ibn Rusyd mengatakan bahwa cara efektif untuk berkomunikasi dengan Qur'an adalah dengan menggunakan tafsir bil ra'yi. ${ }^{32}$

Menurut Saeed tafsir bil ra'yi (based-reason exegesis) memiliki ciri sebagai berikut:

a. Sangat menggantung pada analisis linguistik dan eksplorasi dampak dari penggunaan bahasa dalam sebuah ayat 
b. Menggunakan pembacaan metafora pada ayat-ayat tertentu

c. Menggunakan penafsiran alegoris terhadap ayat-ayat yang secara tekstual bertentangan dengan ra'yu (reason)

d. Menggunakan ijtihad (independent reasoning). ${ }^{33}$

\section{KARAKTERISTIK TEKS AL-OUU'AN BERIMPLIKASI PADA MAKNA}

Dalam menjelaskan bentuk-bentuk ayat di atas, Saeed mengutip pendapat Thabari yang mengkategorisasikan siapa saja yang dapat menafsirkan ayat-ayat dalam al-Qur'an. Pertama, yang dapat memahami dan tahu persis arti sebuah ayat hanyalah Rasulullah. Ayat-ayat yang termasuk pada bagian ini adalah ayat perintah dan larangan. Kedua, yang dapat mengetahui arti dari sebuah ayat hanyalah Allah. Yang termasuk dari ayat ini adalah perkara ghaib seperti hari akhir, surga, neraka dan sebagainya. Ketiga, orang yang akbar dengan bahasa Arab. ${ }^{34}$

Pendapat di atas selaras dengan argumentasi Ibn Abbas yang membagi ayat alQur'an dalam empat kategori: Pertama, ayat yang dapat dipahami oleh orang awam dengan berbagai keterbatasan ilmunya. Kedua, ayat yang hanya dapat dipahami oleh orang-orang Arab, karena al-Qur'an berbahasa Arab, tentu ada hal-hal khusus yang tidak diketahui oleh orang di luar Arab, misal saja masalah budaya. Ketiga, ayat alQur'an yang hanya dipahami oleh ulama karena ilmunya. Keempat, ayat yang hanya Allah yang tahu persis artinya. ${ }^{35}$

Pendapat di atas jelas sekali memberikan peluang kepada para ulama untuk menafsirkan al-Qur'an dengan berbagai ilmunya. Sebab Rasulullah, selama hidupnya, tidak memberikan penafsiran al-Qur'an secara utuh. Artinya, dari $6236^{36}$ ayat masih banyak yang perlu ditafsirkan, dan hal tersebut merupakan tugas ulama muta'akhirin. Pendapat di atas juga memberikan penjelasan bahwa teks al-Qur'an mememiliki karakteristik tersendiri, dan setiap kareakter tentu membawa implikasi penafsiran.

Saeed membagi teks al-Qur'an menjadi beberapa empat jenis; Pertama, teks yang terkait dengan perkara teologis, memuat di dalamnya perkara ghaib; Kedua, teks yang berorientasi pada sejarah; Ketiga, teks yang terkait dengan perumpamaan-perumpamaan dan kisah-kisah; ${ }^{37}$ Keempat, adalah teks yang bicara mengenai hukum. Dari keempat bentuk teks tersebut, Saeed berpandangan bahwa untuk teks yang terkait dengan masalah teologi/ghaib seperti surga, neraka dan kiamat, termasuk teks yang tidak perlu ditafsirkan, atau maknanya dikembalikan pada literalnya saja. Sementara untuk jenis teks yang kedua yang berorientasi pada sejarah masih membutuhkan data tambahan, fakta dan berbagai informasi sejarah lainnya. Untuk jenis ayat yang terakhir, tidak semuanya harus ditafsirkan secara literal. ${ }^{38}$ Sebab beberapa cerita bisa memuat metafora. Sedangkan yang terakhir ayat hukum, dapat ditafsirkan dengan merujuk pada kondisi Mekah dan Madinah pada waktu tersebut. ${ }^{39}$

Saeed juga berpandangan dalam penerapan socio-historical context tidak dapat diterapkan pada semua ayat. Maka ia, sebagaimana ulama klasik lainnya, setuju dengan pembagian dua karakteristik ayat hukum, yakni mutable (dapat berubah) dan immutable (ajeg, tidak berubah). Ayat-ayat yang memuat hukum-etis (syari'at), dan mu'amalah biasanya masuk dalam mutable. Sementara itu untuk urusan ibadah termasuk yang immutable..$^{40}$ Selanjutnya ia juga 
berpandangan bahwa ayat yang dapat ditafsirkan dengan pendekatan ini juga tidak semuanya. Ulama membagi dua bentuk ayat terkait kriteria dapat dan tidak ditafsirkan, yakni muhkamat dan mutasyabihat.

Menurutnya ayat muhkam adalah ayat yang clear, jelas, tidak memuat berbagai makna yang ambigu (musyatarak). Sementara yang mutasyabih menurutnya adalah ayat yang unclear, tidak jelas, mengandung konotasi, dan berbagai metafora. Ayat mutasyabih inilah yang membutuhkan penafsiran, demikian pendapatnya. ${ }^{41}$

\section{LANGKAH-LANGKAH KONTEISSTUALISASI AL-QUR'AN}

Dari uraian panjang lebar di atas, akhirnya memunculkan pertanyaan, bagaimana mengaplikasikan gagasan tersebut dalam bentuk yang lebih operasional? Saeed telah mengantisipasi perntanyaan tesebut dengan baik. Ia membuat langkah-langkah operasional tafsir kontekstual sebagai berikut:

\section{Langkah I}

Menemukan dunia teks

\section{Langkah II}

Analisis kritis, maksudnya mengkaji apa yang diinginkan al-Qur'an tanpa dikaitkan dengan penerima wahyu dan kondisi saat ini. Adapun beberapa aspek yang dibahas antara lain: linguistik (mecakup makna kata, frase, syntax, gramatikal, dan qira'at).

1) Literary context (konteks teks), maksudnya menjelaskan konteks ayat atau surah, misalnya menjelaskan mana yang datang duluan dan belakangan.

2) Literary form (bentuk teks), maksudnya mengindentifikasi jenis teks, apakah ini termasuk teks sejarah, teologi, hukum, dan sebagainya.

3) Parallel texts (keterkaitan teks), yakni mengeksplorasi dan mengumpulkan ayatayat terkait dengan tema.

4) Presecedents, maksudnya mengindentifikasi teks yang memiliki kesamaan isi dan maksud.

\section{Langkah III}

Mengaitkan teks pada penerima wahyu pertama al-Qur'an atau makna teks bagi penerima wahyu pertama. Ada beberapa hal yang perlu diperhatikan:

1) Contextual analysis (analisis kontekstual), menganalisis teks dengan mempertimbangkan berbagai bentuk sumber sejarah, social, politik, dan sebagainya yang terjadi di Hijaz.

2) Mengidentifikasi sifat dari teks, termasuk hukum, etika dan sebagainya.

3) Menggaris bawahi teks-teks yang menjadi focus pembahasan.

4) Menemukan garis merah teks yang digaris bawahi tadi dengan tujuan-tujuan alQur'an.

5) Mengevaluasi bagaimana teks diterima oleh komunitas pertama dan bagaimana menafsirkan, memahami dan menerapkannya.

\section{Langkah IV}

Mengaitkan teks dengan konteks saat ini.

Hal-hal yang perlu diperhatikan antara lain:

1) Menentukan masalah-masalah dan kebutuhan-kebutuhan yang relevan dengan pesan-pesan dalam teks.

2) Mengeksplorasi nilai-nilai sosial, politik, ekonomi dan konteks budaya yang relevan dengan teks.

3) Mengeksplorasi nilai-nilai dan normanorma saat ini, yang sesuai dengan pesan teks.

4) Mengkomparasikan konteks saat ini dengan konteks teks, khususnya persamaan dan perbedaannya. 
5) Membuat keterkaitan makna teks yang dipahami saat ini dengan makna teks, dengan mengambil persamaan dan perbedaannya.

6) Mengidentifikasi universalias dan lokalitas (kekhususan) pesan apakah terkait dan tidak dengan tujuan-tujuan teks. ${ }^{42}$

Adapun contoh dari penafsiran Saeed sebagai berikut:

Today, in many Muslim communities, women are economically independent thanks to educational and employment opportunities. They attend school and university like their male counterparts, and equip themselves to play important roles in society. Early ideas about the intellectual inferiority of women have been proved to be baseless; in fact, women are ahead of men on many fronts in educational achievement. In many countries, women can become heads of state or assume other senior positions and this is despite the arguments put forward by some Muslims, who argue that women should not assume such positions. In the light of the transformation of the roles and status of women, should we still argue for maintaining the only reading of the inheritance verse entertained by Muslim scholars over the past 1,400 years, or should we attempt to explore other possible readings? My argument is that we have no reason not to. ${ }^{43}$

Menurut Saeed, saat ini perempuan sudah lebih mandiri dalam ekonomi. Para wanita saat ini juga lebih terpelajar. Bahkan di beberapa daerah perempuan menjadi pemimpin, baik dalam negara maupun perusahaan. Dengan kondisi seperti itu apakah cara pandangan 1400 tahun terhadap wanita tidak berubah?

\section{KESIMPULAN}

Dari uraian panjang lebar di atas, ada beberapa poin penting yang dapat disimpulkan pada sub bab berikut: Metode kontekstual merujuk pada beberapa prinsip, yakni teks terikat dengan teks, metode kontekstual sudah ada sejak periode awal, penafsiran kontekstual membutuh tafsir bil ra'yi, dan karakteristik teks mempengaruhi penafsiran. Adapun langkah-langkah operasional penafsiran kontekstual Saeed secara singkat dapat digambarkan sebagai berikut: Langkah pertama mengidentifikasi dunia teks. Kedua menganalisis teks secara kritis, mulai dari bentuk, sifat, gramatikal sampai qira'at. Ketiga, menganalisis teks dikaitkan dengan komunitas awal penerima wahyu. Keempat, menganalisis tekst dengan kondisi saat ini dan memberikan penafsiran.

\section{CATATAN AKHIR}

1 O.S. Az-Zukhruf/43: 3

2 Abdullah Saeed, Interpreting Qur'an: Towards a Contemporary Approach (London dan New York: Routledge Publishing, 2006), hlm. 112-113.

3 http://www.law.unimelb.edu.au/ index.cfm?objectid=04687B30-D43B-11E093D10050568D0140

Eusername=Abdullah\%20Saeed diakses 17 Desember 2011. Alamat web ini merupakan situs resmi Melbourne University.

4 http://www.law.unimelb.edu.au/ index.cfm?objectid $=04687$ B30-D43B-11E093D10050568D0140

Eusername=Abdullah\%20Saeed diakses 17 Desember 2011. Alamat web ini merupakan situs resmi Melbourne University.

5 http://www.allbookstores.com/Abdullah-Saeed/author/ 1 diakses tanggal 17 Desember 2011

6 Hermeneutika dalam fase inilah yang sering diserang oleh ulama konservatif, karena mereka menganggap bahwa hermeneutika lebih cocok untuk Bible yang kebenarannya dipertanyakan. Sedangkan al-Our'an kebenarannya dianggap final, maka tidak perlu hermeneutik.

7 Syahiron Syamsudin, Hermeneutika dan Pengembangan Ulumul Qur'an (Yogyakarta: Nawasea, 2011), hlm. 1120. 
8 Farid Essack, The Qur'an: A User's Guide (England: Oneworld Publications, 2007), hlm. 142.

9 Saad Abdul Wahid, Mengkaji Ulang Ulumul Qur'an (Yogyakarta: Suara Muhammadiyah, 2011), hlm.

10 Farid Essack, The Qur'an..., hlm. 143.

11 Dalam salah satu artikelnya, Abdullah Saeed menjelaskan dengan gamblang bahwa seseorang dalam memahami al-Qur'an harus menjadikan setting historis sebagai pendekatannya. 'Contextualizing' dalam A. Rippin (ed), The Blackwell Companion to the Qu'ran, 2006, hlm. 38.

12 Abdullah Saeed juga menegaskan secara tidak langsung, bahwa bahasa adalah alat penting untuk mengetahui arti al-Qur'an. Sebab al-Qur'an diwahyukan dengan bahasa. Namun seseorang jangan terjebak pada bahasa saja. la harus keluar melihat historisitas dari ayat tersebut. Abdullah Saeed, The Qur'an: An Introduction (London dan New York, Raoutledge, 2008), hlm. 13-14

13 Farid Esack, Al-Qur'an..., hlm. 142. Sepertinya Esack terpengaruh dengan ide dari Hermeneutikanya Gadamer. Dalam Truth and Method, la juga menjelaskan hal serupa. Baginya pemahaman baru dapat tercapai bila ada peleburan horizon antara penafsir dan audience. Lihat Hans Georg Gadamer, Truth and Method, (London-New York: Continum, 2006), hlm. 385387.

14 Farid Esack, The Al-Our'an..., hlm. 143.

15 Abdullah Saeed, Interpreting..., hlm. 25

16 Abdullah Saeed, Interpreting..., hlm. 1.

17 Abdullah Saeed, Menyoal Bank Syari'ah: Kritik atas Interpretasi Bunga Bank Kaum Neo Revivalis (Jakarta: Paramadina, 1996), hlm. 27.

18 Abdullah Saeed, Islam In Australia, (South Australia: Griffin Press, 2003), hlm. v.

19 Abdullah Saeed, Interpreting..., hlm. 2.

20 Asbab an-Nuzul adalah peristiwa-peristiwa dan pertanyaan-pertanyaan yang menyebabkan sebuah ayat diturunkan. Lihat Saad Abdul Wahid, Mengkaji Ulang Ilmu Al-Qur'an dan Ilmu Tafsir, Yogyakarta: Suara Muhammadiyah, 2011, hlm. 178. Sementara qiyas berarti mencari kesamaan peristiwa yang terjadi di masa lalu dengan sekarang, tanpa memperhatikan konteks masa lalu.

21 Abdullah Saeed, The Qur'an..., 2008, hlm. i

22 Abdullah Saeed, The Qur'an..., hlm. 2.

23 Abdullah Saeed, Interpreting..., hlm. 105.

24 Abdullah Saeed, Interpreting..., hlm. 3.

25 Abdullah Saeed, Interpreting..., hlm. 105.

26 Muhammad Abid Al-Jabiri, Agama, Negara dan Penerapan Syari'ah, (Yogyakarta: Fajar Pustaka, 2001), hlm. 45.

27 Abdullah Saeed, Interpreting...h.h. 91.

28 Kuntowijoyo, Paradigma Islam: Interpretasi untuk Aksi (Bandung: Mizan, 1999), hlm. 185-194.
29 Abdullah Saeed, Islamic Thought: An Introduction (London dan New York: Routledge, 2006), hlm. 150.

30 Abdullah Saeed, The Qur'an..., hlm. 221.

31 Abdullah Saeed, The Qur'an..., hlm. 181.

32 Abdullah Saeed, The Qur'an..., hlm. 181.

33 Abdullah Saeed, The Qur'an..., hlm. 182

34 Abdullah Saeed, , Interpreting...hlm. 90.

35 Ar-Razi, Mafatih al-Ghaib Vol. IV, tt., tp., hlm. 116 dalam Maktabah Syamilah.

36 Perhitungan ini menggunakan mushaf usmani yang umum beredar di masyarakat. Dalam hitungan ini tidak memasukkan basmalah dalam surah. Kalau basmalah dimasukkan berjumlah maka jumlah ayatnya 6348 .

37 Abdullah Saeed, Interpreting..., hlm. 91-100. Bandingkan dengan pandangan Abdullah Saeed, The Qur'an..., hlm.75-78. Dalam buku ini ia menambahkan satu jenis teks, yakni teks yang bicara tentang hukum.

38 Abdullah Saeed, The Qur'an..., hlm. 100-101.

39 Abdullah Saeed, The Qur'an..., hlm. 78.

40 Abdullah Saeed, Interpreting...hlm. 123. Lihat juga Abdullah Saeed, The Qur'an..., hlm. 188-189.

41 Abdullah Saeed, The Qur'an..., hlm. 183-184.

42 Abdullah Saeed, Interpreting..., hlm. 149-153.

43 Abdullah Saeed, Interpreting..., hlm. 121-122.

\section{DAFTAR PUSTAKA}

Al-Jabiri, Muhammad Abid. 2001. Agama, Negara dan Penerapan Syari'ah, Yogyakarta: Fajar Pustaka.

Ar-Razi, Fakrudin. Tanpa tahun. Mafatih al-Ghaib Vol. IV, tt., tp., dalam Maktabah Syamilah.

Esack, Farid. 2007. The Qur'an: A User's Guide, England: Oneworld Publications.

Gadamer, Hans Georg. 2006. Truth and Method, London dan New York: Continum.

Kuntowijoyo 1999. Paradigma Islam: Interpretasi untuk Aksi, Bandung: Mizan.

Rippin, Andrew (ed). 2006. The Blackwell Companion to the Qu'ran, US, UK, dan Australia: Blackwell Publishing.

Saeed, Abdullah. 2006. Interpreting Qur'an: Towards a Contemporary Approach, London dan New York: Routledge Publishing. 2003. Islam In Australia, South Australia: Griffin Press. 2006. Islamic Thought: An Introduction, London dan New York: Routledge. 1996. Menyoal Bank Syari'ah: Kritik atas Interpretasi Bunga Bank Kaum Neo Revivalis, Jakarta: Paramadina.

2008. The Qur'an: An Introduction, London dan New York, Raoutledge.

Samsudin, Syahiron. 2009. Hermeneutika dan Pengembangan Ulumul Qur'an, Yogyakarta: Nawasea. Wahid, Saad Abdul. 2011. Mengkaji Ulang Ulumul Qur'an, Yogyakarta: Suara Muhammadiyah. 


\section{Sumber Website:}

http://www.allbookstores.com/Abdullah-Saeed/author/1 diakses tanggal 17 Desember 2011

http://www.law.unimelb.edu.au/

index.cfm?objectid=04687B30-D43B-11EO-

93D10050568D0140

Eusername=Abdullah\%20Saeed diakses 17 Desember

2011. Alamat web ini merupakan situs resmi

Melbourne University. 